\title{
Quantitative Assessment of Building Constructability Using BIM and 4D Simulation
}

\author{
Cheng Zhang ${ }^{1}$, Tarek Zayed ${ }^{2}$, Wissam Hijazi ${ }^{2}$, Sabah Alkass ${ }^{3}$ \\ ${ }^{1}$ Department of Civil Engineering, Xi'an Jiaotong-Liverpool University, Suzhou, China \\ ${ }^{2}$ Department of Building, Civil and Environmental Engineering, Concordia University, Montreal, Canada \\ ${ }^{3}$ Department of Engineering, University of Sharja, Sharjah, United Arab Emirates \\ Email: cheng.zhang@xjtlu.edu.cn, zayed@encs.concordia.ca, salkass@sharjah.ac.ae
}

Received 17 November 2015; accepted 6 June 2016; published 9 June 2016

Copyright (C) 2016 by authors and Scientific Research Publishing Inc.

This work is licensed under the Creative Commons Attribution International License (CC BY). http://creativecommons.org/licenses/by/4.0/

(c) (i) Open Access

\begin{abstract}
Despite the fact that applying constructability concepts in building designs have led to savings estimated within a range of $1 \%$ to $14 \%$ of the capital cost, the construction industry still lacks an advanced tool to assess and check for constructability implementations in designs. Therefore, the objective of this research is to propose a quantitative assessment of building constructability, which transforms the subjective assessment of constructability knowledge to a quantified value so that it is easy to analyze and improve building design. The proposed methodology uses the advancement of object oriented Building Information Model (BIM) and 4D simulation model to serve as a data repository models for the constructability assessment platform. Factors affecting constructability of building designs have been identified and relatively weighted using Analytical Hierarchy Process (AHP) technique based on a questionnaire survey collected throughout the Canadian provinces. Evaluation criteria are also developed to assist the designer to evaluate the design proposals. The outcome shows that the proposed method provides the designer an accurate and faster mode in evaluating project constructability by using the parametric features from BIM and taking the advantage of spatial relationship between building components.
\end{abstract}

\section{Keywords}

Constructability, BIM, Simulation, Quantitative Assessment

\section{Introduction}

Construction is a dynamic, complex, as well as fragmented process, and the traditional system of construction 
separates the two main disciplines of design and construction, where designers and contractors rarely communicate before the initiation of the construction phase. Early in 1982, The Business Roundtable defined a "constructability program" where a potential return on investment of 10:1 was reported by applying constructability [1]. National Institute of Standards and Technology (NIST) conducted a study in 2004 and reported that the lack of Architecture/Engineering/Construction (AEC) interoperable software was costing the industry \$15.8 Billion annually [2].

The commonly quoted definition of constructability by the Construction Industry Research and Information Association (CIRIA) is "the extent to which the design of a building facilitates ease of construction, subject to the overall requirements for the completed building" [3]. This signifies the fact that building design has a critical impact on constructability. Constructability of designs have complex relationships with time, cost, and quality performance, which are often ignored by building clients until construction starts, causing surprises and concerns [4]. Hence, by translating the abstract concept of constructability into something physical and recognizable to project stakeholders, improvement and assessment of constructability of designs are applicable. One of the main approaches to improve and enhance constructability is through quantified assessment of designs. Quantified assessment enables an objective evaluation of constructability attributes while results are comparable [5].

With the continuous advancement in technologies, new techniques are constantly being developed in order to improve engineering implementations for the construction industry. One of these promising developments is Building Information Modeling (BIM) where it facilitates a more integrated design and construction process that results in better quality buildings at lower cost and reduced project duration [6]. The American Society of Civil Engineer (ASCE) reports that BIM technology can be used to validate a new constructible tool [7]. BIM provides the construction community a complete 3D database that can be used for estimating, scheduling, detailing, advance bill production, automated shop drawing, and construction planning for all of the trades. In addition, by adding time information to the BIM model, 4D models facilitate the testing of different design and execution sequencing alternatives so as to achieve better constructability. Therefore, by integrating BIM and 4D simulation, quantitatively assessing the constructability of a building design becomes a novel, feasible and necessary method. The present paper describes the proposed new method and relative implementation and development.

\section{Background}

The benefits of improved constructability have been associated with the time, cost, quality, and safety performance of a project, together with other intangible benefits. Quantifying assessment of designs, constructability review, and implementation of constructability programmers are the three most commonly employed approaches. Quantifying assessment of designs enables an objective evaluation of constructability attributes since results are comparable. Using this approach, two issues were addressed. On one hand, it is reasonably practicable and manageable for assessments to be made because it is done using the finished design product rather than evaluating the design process. On the other hand, it is difficult to comprehensively take into account all relevant factors affecting constructability into the assessment system [5].

Singapore has pioneered in the field of quantifying constructability based on a scheme known as the Buildable Design Appraisal System (BDAS). The concept is based on a "3S" design principle in which a design is tested for constructability issues with respect to Standardization, Simplicity and Single Integrated Elements. A similar approach was used for assessing constructability proposed for the Hong Kong construction industry in 2007 [5]. A constructability multi-attribute system (BMAS) was developed for assessing constructability of designs in Malaysia [8]. The assessment was based on 6 principles with identified factors for each principle which were developed through a literature review, questionnaire survey and brainstorming sessions. Another assessment method based on cognitive models (CM) was proposed for constructability assessment for steel frame structures [9]. It was based on the use of interviewing techniques to understand problem solving and the development of knowledge models for automated constructability assessment. [10] developed a fuzzy Quality Function Deployment (QFD) system to support constructible design decision making. It provided a systematic and structured method to support the integrated decision-making process of constructible designs, and applied a fuzzy set theory to facilitate the processing of design-relevant QFD information.

It was found that previous assessment platforms were in complex calculations, dependent on governmental benchmarks, and lack of time factor. Detailed comparison can be found in [11]. In addition, working schedule was not considered in any of the previous work introduced above. The analysis of the time module throughout 
all construction phases was essential for any constructability evaluation, as indicated by [12]. Therefore, there is a need for an integrated assessment platform to provide the user a project specified model, with clearly defined rules, understandable criteria, and flexible interactive system.

As discussed in the Introduction, BIM is playing a crucial role in research and development fields of construction information integration and interoperability. BIM is defined as the creation and use of coordinated, consistent, computable information about a building project. These various forms of information had a parametric nature where they can be used for design decision making, production of high-quality construction documents, prediction of building performance, cost estimating, and construction planning [13]. By having the possibility to build the whole project virtually before physical construction begins, BIM adds a level of accuracy to both quantities and quality issues that overcomes the shortenings found when traditional processes of design and documentation are used. Traditional 2D and 3D CAD programs don't represent a space because it doesn't exist as a distinct physical entity. However, a space entity is a fundamental part of a BIM model, and includes the proper relationships to its corresponding walls, ceilings, floors, etc. Thus, spatial information needed for constructability analysis can be easily obtained from an application using a BIM data model, whereas several complex calculations had to be required to derive the same information from an application using a traditional geometric data model [14].

As stated earlier, certain constructability factors are of a qualitative nature which makes it exceptionally difficult to quantify their impact on design. For example, many studies have been done on analyzing material access throughout the construction site, and all the contributions included only ideas and knowledge bases to improve proper material accessibility ([15] [16]). There is a little evidence in literature that reported a formal procedure or standard process for material access analysis. In order to analyze qualitative constructability factors, the present research argues that visual analysis can be used as basis for studying such qualitative factors if they were properly associated with constructability knowledge.

In addition, time information can be integrated into the BIM model, which utilizes a three-dimensional project geometry into an environment where the effect of time schedule over construction can be visualized. A virtual object-oriented 4D model had the potential to support automated constructability assessment and to assist a project team in identifying constructability issues early in the design and construction phases [17]. This improved the identification of possible mistakes or conflicts done unknowingly at an early stage of a construction project, and thus enabled project stakeholders to optimize the construction schedule as much as possible [18].

The authors of the present paper have been exploring the integration of quantitative constructability assessment with BIM and 4D models for a long time. Based on our previous research results ([19] [20]), a complete methodology and implementation are described in the present paper.

\section{Objectives}

The objectives of the present paper are:

1) to propose a new methodology for assessing constructability of building designs quantitatively considering both quantitative and qualitative issues;

2) to explore the added value for using BIM/4D concept in constructability assessment;

3) to develop a platform to integrate all factors that affect constructability to be associated with BIM components.

\section{Proposed Methodology}

Figure 1 shows the proposed methodology. The assessment system consists of three modules, which are BIM/4D model, Integrated Data Model, and the User Interface. They are represented by dashed boxes in the figure. Data from the BIM/4D model and the Integrated Data Model act as Constructability Input, which are evaluated through the developed tool. The dotted boxes represent the groups that each item belongs to. First of all, factors that affect constructability are identified based on literature review. Based on the work of the Construction Industry Institute (CII) in the field of constructability knowledge, eight design-relevant constructability principles are recorded [21]: (1) Basic design approaches consider major construction methods such as modularization or preassembly; (2) Modular/preassembly designs are prepared to facilitate fabrication, transportation, and installation; (3) Design elements are standardized including maximum use of manufacturer's standards and standardized components; (4) Designs are configured to enable efficient construction considering issues like 


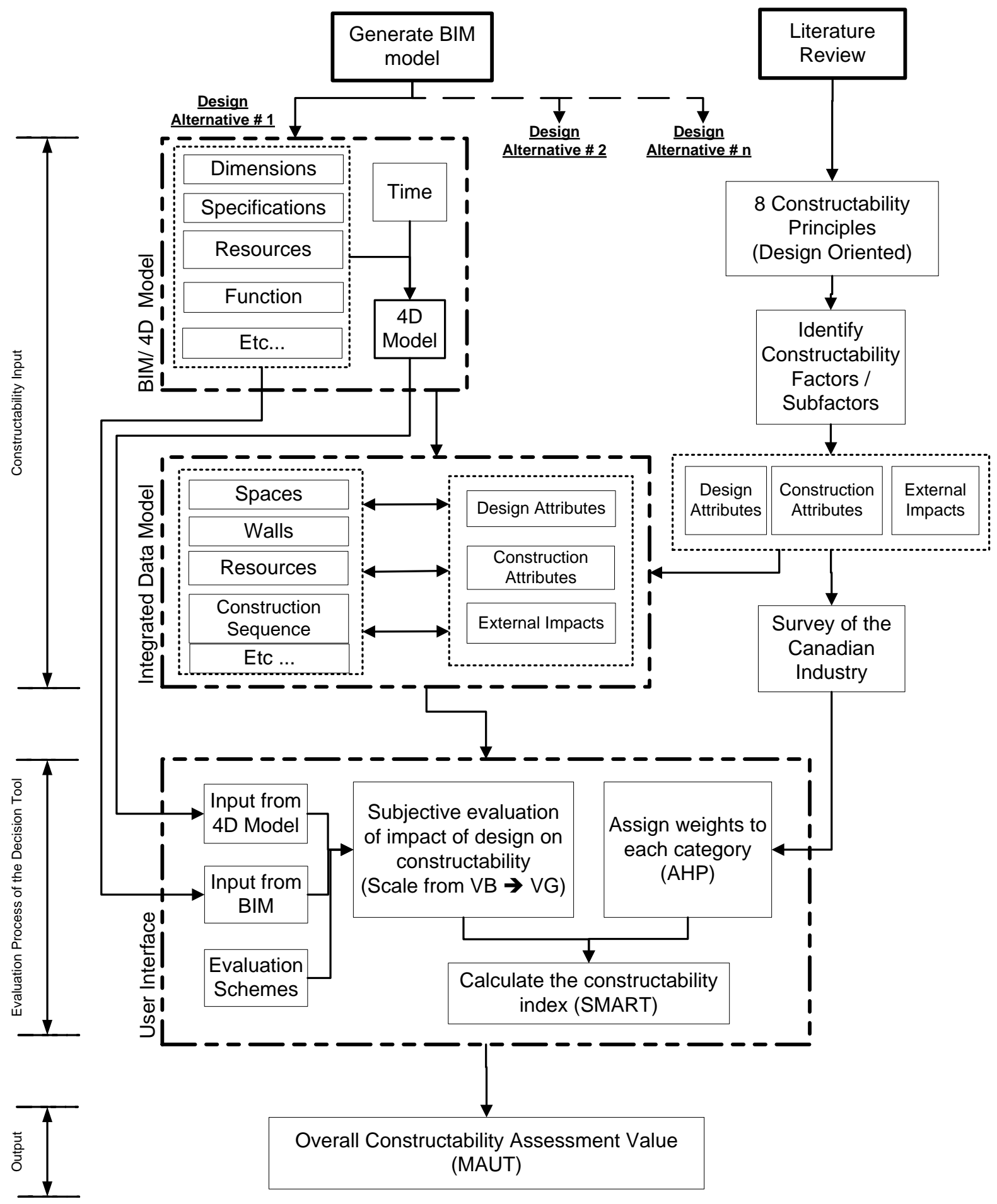

Figure 1. Proposed methodology.

simplicity, flexibility, sequencing of installation, and labor skill and availability; (5) Construction efficiency is considered in specification development including prior review of specs by construction personnel; (6) Designs promote construction accessibility of personnel, materials, and equipment; (7) Designs facilitate construction under adverse weather; and (8) Design and construction sequencing facilitates system turnover and start-up. From those principles, all design-relevant factors affecting constructability of design can be identified. 
Meanwhile, BIM model is developed based on the design. The BIM model includes all the details of Dimensions, Specifications, Resources, Functions, etc. Construction schedule is also integrated to form a 4D model. The integrated Data Model will combine the BIM/4D model with Design Attributes, Construction Attributes and the External Impacts to for the Constructability Input.

Constructability factors cannot be easily evaluated by traditional measurement methods or mathematical models due to their qualitative or subjective nature based on review. To address this challenge, a questionnaire survey is proposed to assess the relative importance of the selected factors and to assign weights to them. The survey is forwarded to experienced professionals in the field of design, construction and management disciplines. The relative weight of each factor is calculated using Analytical Hierarchy Process (AHP) [22] technique and imported to the assessment model.

Another aspect of building an assessment model is to develop evaluation criteria that assist the design team in their subjective evaluation of their design proposals. These criteria can aid the designers to rate the output data from BIM and 4D models using a scale that ranges from very bad (VB) to very good (VG), as shown in the bottom part of Figure 1. In order to establish a practical evaluation scheme to evaluate these factors, two main principles must be relied on: general constructability rules and project specific rules. General constructability knowledge is collected from literature reviews and published journal papers and they represent the generic rules criteria. As for the project specific rules, each factor has specific rating criteria relative to project stakeholders' standards and experience. These project rules cannot be generic or standardized since each project is unique, and constructability is subjective from one team to another. The flexibility of the proposed rating and evaluation schemes will address this problem. The present research proposes 16 different rationale criteria list as to meet the concepts of the 16 identified constructability factors. All of the attributes are integrated in the BIM model or identified from the 4D model so that the designer can input the values of these attributes when designing his/ her project.

Using Simple Multi-Attribute Rating Technique (SMART), rating criteria are converted to utility values. SMART was originally developed and formally named by Edwards [23] to implement the principles of multi-attribute theory. Scales are converted into value functions, either by rating the scale values or by linear approximations. Attributes are ranked in the order of their importance and normalized into weights summing to 1.0. More details can be referred to Edwards [23] and Edwards and Barron [24]. The assessment calculation is based on the combination of two decision making techniques AHP and SMART and as per the process presented in Figure 1. More details can be found in the following subsections.

\subsection{Factors Identification}

Factors affecting constructability of designs are studied and identified based on literature reviews, published journal papers, and scientific and academic reports. As shown in Table 1, categories, sub-categories and factors are classified in accordance to 3 main levels. Level \#1 contains the 3 main categories that form the umbrella of all factors affecting constructability of design. Level \#2 contains the sub-categories that constitute factors incorporated in the model. Level \#3 includes those factors that are weighted and used to develop and run the model.

After identifying the sixteen constructability factors, a survey questionnaire is done throughout different Canadian provinces.

\subsection{Criteria Rationale for Evaluation Schemes}

Since constructability is a knowledge based abstract, stakeholders always have different interpretations on how to understand its impact on design. From this sense, what seems easy to construct for a particular construction team, may be difficult for another team. In other words, contractors may execute the work in different manners, but at the end they have to follow a generic construction knowledge based on a specific rationale to get the work properly done. From this perspective, each factor presented in the model is provided with specific rationale criteria in order to assist the user in rating the various constructability factors. These rationales are extracted from the literature and published journal papers. The present research proposes 16 rationale criteria so as to match the 16 identified constructability factors. All of the attributes presented in the section are integrated in the BIM model or identified from the 4D model so that the designer can input the values of these attributes when designing his/ her project. The rationale attributes proposed for each factor are discussed as follows: 
Table 1. Constructability factors identified and incorporated in the model.

\begin{tabular}{|c|c|c|c|c|c|}
\hline Level \#1 & Level \#2 & Level \#3 & Factor Description & Relation to Constructability Concepts & Reference \\
\hline \multirow{5}{*}{$\begin{array}{l}\text { Design } \\
\text { Attributes }\end{array}$} & \multirow{5}{*}{ Standardization } & Prefabrication & $\begin{array}{l}\text { Precast Concrete, } \\
\text { Prefabricated } \\
\text { utility products, etc.... }\end{array}$ & \multirow{2}{*}{$\begin{array}{l}\text { A repeated grid layout will } \\
\text { leads to faster construction } \\
\text { sequences and reduce } \\
\text { production waste. }\end{array}$} & \multirow[t]{2}{*}[25]{,$[26]$} \\
\hline & & Grid Layout & $\begin{array}{l}\text { Horizontal/Vertical/Radial } \\
\text { Grid dimensions }\end{array}$ & & \\
\hline & & $\begin{array}{c}\text { Standard } \\
\text { Dimensions }\end{array}$ & $\begin{array}{l}\text { Dimensions for door, } \\
\text { windows, } \\
\text { partitions, tiles, etc.... }\end{array}$ & $\begin{array}{l}\text { Dimension of building elements } \\
\text { should reflect material sizes and } \\
\text { should be designed to minimize } \\
\text { labour requirements and wastage } \\
\text { of material by special cutting. }\end{array}$ & {$[27]$} \\
\hline & & $\begin{array}{l}\text { Resources’ } \\
\text { Availability }\end{array}$ & $\begin{array}{l}\text { Availability of materials } \\
\text { or special equipments. }\end{array}$ & $\begin{array}{l}\text { Designers should use widely } \\
\text { available materials that can be } \\
\text { economically feasible. }\end{array}$ & {$[25]$} \\
\hline & & $\begin{array}{l}\text { Labour's } \\
\text { Skills }\end{array}$ & $\begin{array}{c}\text { Availability of } \\
\text { special labour skills }\end{array}$ & $\begin{array}{l}\text { Designs should improve } \\
\text { constructability by designing } \\
\text { for economical use of } \\
\text { available skilled workers. }\end{array}$ & [27], [28] \\
\hline \multirow{8}{*}{$\begin{array}{l}\text { Construction } \\
\text { Attributes }\end{array}$} & \multirow{5}{*}{ Installation } & $\begin{array}{l}\text { Construction } \\
\text { Sequence }\end{array}$ & $\begin{array}{c}\text { Sequence of installation } \\
\text { of components. }\end{array}$ & $\begin{array}{l}\text { Appreciating the sequence of } \\
\text { operations and trade } \\
\text { interrelationships on site can } \\
\text { enhance constructability of design. }\end{array}$ & [27] \\
\hline & & $\begin{array}{l}\text { Time under } \\
\text { Ground }\end{array}$ & $\begin{array}{l}\text { Construction time } \\
\text { under ground level. }\end{array}$ & $\begin{array}{l}\text { Reducing the construction } \\
\text { time below ground level } \\
\text { can improve constructability. }\end{array}$ & [28] [29] \\
\hline & & $\begin{array}{l}\text { Building } \\
\text { Envelope }\end{array}$ & $\begin{array}{c}\text { Construction of the } \\
\text { whole building envelope. }\end{array}$ & \multirow{2}{*}{$\begin{array}{l}\text { Designers should facilitate the } \\
\text { enclosure of building at the earliest } \\
\text { possible stage to exclude hind rage } \\
\text { and damage because of bad weather. }\end{array}$} & \multirow{2}{*}{ [28] [29] } \\
\hline & & $\begin{array}{l}\text { Weather } \\
\text { Effect }\end{array}$ & $\begin{array}{l}\text { Effect of climate conditions } \\
\text { on construction work. }\end{array}$ & & \\
\hline & & Safety & $\begin{array}{l}\text { Effect of construction } \\
\text { sequence of workers' safety. }\end{array}$ & $\begin{array}{l}\text { The design should be arranged } \\
\text { so as to facilitate safe working in } \\
\text { foundations and earthworks. }\end{array}$ & [21] \\
\hline & \multirow{3}{*}{ Accessibility } & $\begin{array}{l}\text { Material } \\
\text { Access }\end{array}$ & $\begin{array}{l}\text { Space for material storage } \\
\text { and transportation on site. }\end{array}$ & \multirow{2}{*}{$\begin{array}{c}\text { The efficient location and } \\
\text { distribution of temporary works } \\
\text { and storage areas are necessary } \\
\text { for good buildability. }\end{array}$} & \multirow[b]{2}{*}{ [25] [28] } \\
\hline & & $\begin{array}{l}\text { Personnel } \\
\text { Access }\end{array}$ & $\begin{array}{l}\text { Accessibility of equipments } \\
\text { and tools for and from } \\
\text { different site locations. }\end{array}$ & & \\
\hline & & $\begin{array}{l}\text { Equipment } \\
\text { Access }\end{array}$ & $\begin{array}{l}\text { Accessibility of personnel } \\
\text { for different site locations. }\end{array}$ & $\begin{array}{l}\text { Designers must consider the } \\
\text { contractor problems of access to } \\
\text { and around construction sites. }\end{array}$ & [25] \\
\hline \multirow{2}{*}{$\begin{array}{c}\text { Site } \\
\text { Impacts }\end{array}$} & \multirow{2}{*}{$\begin{array}{l}\text { Adjacent } \\
\text { Structures }\end{array}$} & $\begin{array}{l}\text { To Adjacent } \\
\text { Foundation }\end{array}$ & $\begin{array}{l}\text { Effect of current construction } \\
\text { to adjacent constructions. }\end{array}$ & \multirow{2}{*}{$\begin{array}{c}\text { Site conditions should be thoroughly } \\
\text { investigated to avoid subsequent } \\
\text { delays thoroughly after } \\
\text { construction has commenced. }\end{array}$} & \multirow{2}{*}{ [29] } \\
\hline & & To Infrastructure & $\begin{array}{l}\text { Effect of current construction } \\
\text { to adjacent or nearby } \\
\text { infrastructure constructions. }\end{array}$ & & \\
\hline
\end{tabular}

- Prefabrication: Prefabrication has a direct impact on three main construction drivers: cost, schedule and workforces issue. From a constructability point of view the more fabricated components are involved in the design, the more the positive impact is on constructability. The attributes related to this factor are:

a) Prefabrication: Prefabrication is defined as "a manufacturing process, generally taking place at a specialized facility, in which various materials are joined to form a component part of a final installation” [30]. Any component that is manufactured offsite and is not a complete system can be considered to be prefabricated [31]. 
b) Preassembly: A common definition for preassembly is "a process by which various materials, prefabricated components, and/or equipment are joined together at a remote location for subsequent installation as a unit" [30]. The preassembly process can involve adapting sequential activities into ones that are parallel. Preassembly is generally considered to be a combination of prefabrication and modularization. It may use fabricated components made offsite and then assembled near the site. These units can then be installed at the site, similar to modules [31].

- Grid Layout: According to Code of Practice on Buildability [26], Standardization refers to repetition of grids, sizes of components and connection details. A repeated grid layout will facilitate faster construction whether formwork or precast components are used. A modularized grid layout facilitates fabrication of components, reduce material waste and make installation sequence faster [32]. Attributes related to this factor are: Horizontal grid, Vertical grid, and Circular grid.

- Standard Dimension: this factor checks all components of the buildings if its constitute parts have a standard dimension or not. The attributes are: Standard components, and Custom made components.

- Component Flexibility: Flexibility is characterized as the ability of a system to cope with unforeseen changes [33]. Product flexibility is defined as the degree of responsiveness (or adaptability) for any future change in a product design. Making a design more flexible leads to a reduction in redesign cost and plays a significant role in responding faster to customer feedbacks by allowing quicker updates in the products and achieving higher levels of performance in a short span of time [34]. The 4 main attributes to analyze flexibility of design components are:

a) Potential for change: The user has to identify each component whether a particular component has a potential to change or not.

b) Effect of change: If the component has a potential to change, the user must identify the effect of the change from a 3 point scale; Low, Moderate or High. Otherwise he/she will state NA for not applicable.

c) Readiness for change: If the potential for change was positive, the user must state if the construction team is ready for the change or not. For example, the construction team must identify whether they are ready to change an internal partition $125 \mathrm{~mm}$ to a $145 \mathrm{~mm}$ thick with a 2 hour fire rated protection or not.

d) Position flexibility: This attribute addresses flexibility more specifically concerning orientation and horizontal display.

- Resources Availability: Availability of resources is considered one of the main factors for addressing constructability of a given design. Resources here mean ordinary labor, material or equipment. Thus attributes related to this factor are: Equipment availability, Personnel availability, and Material availability.

- Labor Availability: Labor here stands for a specialized skilled labor or talent. Some activities needs a particular kind of labor and the unavailability of this resource can cause a delay of a construction activity. Those attributes related to this factor are: Special skill needed, and Special skill unneeded.

- Construction Sequence: Attributes related to this factor are [16]:

a) Physical relationships among components: Building components are spatially restricted; weather protected, or gravity supported by other components. Activity sequencing has to respond to these inter-component relationships.

b) Trade interaction: Activity sequencing also responds to different ways in which trades affect each other during construction phase.

c) Path interference: Building components have to be moved around jobsite in order to be installed. Activity sequence has to guarantee an interference-free path for installation of any component.

d) Code regulation: Activity sequencing is also response to construction-phase safety considerations.

- Time underground: must be calculated as its value must be taken into consideration to assess the overall constructability. The attributes used for this factor are: Total construction time for activities at the underground level, and Total project duration.

- Building Envelope: The study of building envelope can ensure proper enclosure analysis of the project. This factor is used in the overall constructability assessment. The attributes used for this factor are: Number of days to finish all external activities, and Total project duration.

- Weather Effect: The two attributes needed to analyze this factor are: Number of days with expected bad weather, and Number of planned dates that match the same bad weather days.

- Safety: Safety issues must be recognized throughout all stages of the design phase [35]. The main important issues to be addressed by designers are: 
a) Hazardous locations: Chemical materials, gas containers or unsafe openings must be well identified as to be prevented when planning for work spaces and material access.

b) Parapet height: Height of minimum 42 inch should be provided immediate guardrail thus eliminating the need to construct one and improving safety during construction phase.

c) Window sill height: The same rule for parapet height is applied here.

d) Identify components to be fabricated on ground then placed in place: In order to reduce exposure to falls from elevation and the risk of workers being struck by falling objects.

e) Identify permanent stairways and walkways (have priority to be constructed first): To minimize the use of temporary scaffolding.

f) Identify overhead power lines for cranes: To reduce contact with high voltages.

g) Overtime periods: Overtime periods may cause fatigues that reduce the alert of workers during construction.

- Material Access: To insure proper material accessibility throughout different site locations, specific space allocations must be properly defined. Diverse space areas based on literature findings [36] are listed here and they form the main attributes used to analyze the material access factor from any given 4D model: Unloading area, Staging area, Storage area, Prefabrication area, Working area, Protected area, Material path, and Debris path.

- Personnel Access: Similar to the previous factor, four attributes are proposed here to insure proper personnel path: Hazardous path, Hazardous locations, Stair cases accessibility, and Scaffolding area.

- Equipment Access: Equipment space is defined as a space occupied by a resource or temporary facility which is used to support other activity work elements. The analysis of equipment space can lead to the analysis of the equipment access using these attributes: Unloading area, Storage area, Working area, and Equipment occupied place.

- Effect to Adjacent Foundation: Like adjacent building structures (basement, retaining walls, foundations, etc...). Two attributes are identified for this factor: Identify exciting adjacent foundation, and Distance between adjacent foundation and new building.

- Effect to Infrastructure: Like adjacent sewage system or underground power line installations. The two attributes identified for this factor are: Identify exciting adjacent infrastructure, and Distance between adjacent infrastructure and new building.

\subsection{Data Identification from the BIM Models}

To insure proper and accurate output of constructability data to the proposed assessment model, a special technique is proposed and developed to insure proper constructability input to the design. This aspect is achieved by modifying certain aspects of the BIM and 4D models. The technique also must be generic so that whatever kind of BIM vendor the user is working on, the assessment method works properly.

Each constructability attribute identified is linked to the BIM model in the form of a shared parameter. A shared parameter is saved in a universal format with the intention that each design component in the BIM model has the possibility of acquiring constructability inputs. The purpose of this approach is to facilitate the designer adding accurate constructability information to the model while designing the building. Only attributes that can be modified from BIM models are saved in the shared parameter file. These parameters and their input types criteria are: Labor availability (Yes/No), Material availability (Yes/No), Equipment availability (Yes/No), Spe cial Skill Labor (Yes/No), Prefabrication (Yes/No), Preassembled (Yes/No), Standard dimension (Yes/No), Flex_Effect of change (Low/Moderate/High), Flex_Position Flexibility (Yes/No), Flex_Potential for change (Yes/No), Flex_Readiness for change (Yes/No).Shared parameters are saved in a text file (*.txt) so that they can be loaded and used easily by any BIM vendor.

The output of the 4D model is in the form of either a simulation video or snap-shot pictures captured on a preplanned time schedule. Figure 2(a) and Figure 2(b) show two snap-shot examples of a 4D model and how with constructability interpretation can be made using visual analysis.

The constructability factors previously incorporated with the $4 \mathrm{D}$ model needs two main visual aspects to insure proper evaluation:

- Components: The relationship between the time duration and the physical characteristics of each building component is clear in the 4D model and is used to study the following factors: Construction sequence, Time underground, Building envelope, Weather effect, Safety, To adjacent foundation, and To infrastructure. 


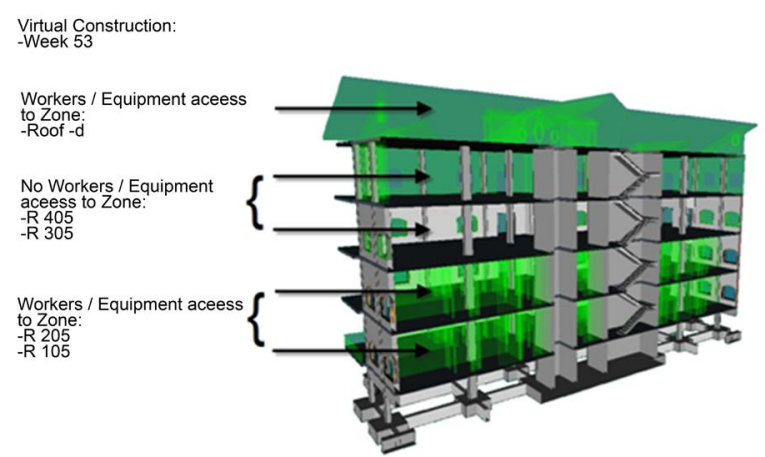

(a)

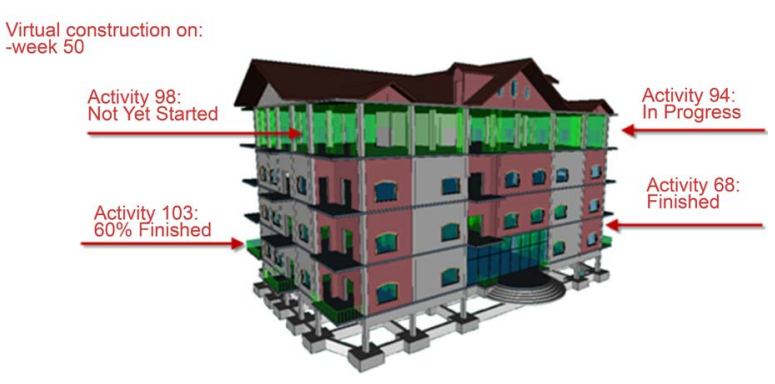

(b)

Figure 2. Examples of a 4D visual interpretation.

- Space Volumes and Paths: By identifying work spaces and worker's path in the BIM model, as mass volumes and polylines, working space allocations and resource accessibility can be studied from the 4D model. These aspects will be used to study the following factors: Material access, Personnel access, and Equipment access.

The general idea behind developing the assessment model is based on transforming the subjective assessment of constructability knowledge to a quantified value so that it is easy to analyze and improve. From this perspective, the model has to take into consideration two main attributes, the weight of each factor and the utility value of each factor. Constructability index reflects the impact value of a particular factor on the overall constructability score and is calculated in a way that is presented in [19]. The final generated score represents the overall level of constructability satisfaction in a particular building design.

\section{Constructability Assessment Model Development and Implementation}

\subsection{Data Collection}

A questionnaire was sent to sixty-two experts (architects, designers, consultants), among which fifteen feedbacks were received, giving a response rate of $24 \%$. The relative weight of each factor at each level of the hierarchy is collected. This could be the answer to the question of "What is the importance of each factor in contributing to impact on constructability?” The questionnaire survey asked the participants to perform a pair wise comparison for each factor found under each level. They were provided with a 9 point scale that ranges from "Equally Preferred" to "Extremely Preferred" as proposed by Saaty [22]. The sample form was designed in a very simple manner as to record the experts' opinion concerning importance of factors affecting constructability easily. All the factors recorded in level \#3 are categorized with respect to their main category so that the respondent performs their rating with respect to these specified categories. For example: flexibility, resources availability and skills labors' availability are 3 factors found in the sub-category "economical impact of design" which falls in under the main category "Design Attributes". Thus pair wise comparisons are made throughout these 3 levels separately.

Reliability analysis is applied to the collected data to estimate the reliability of the questionnaire responses. Cronbach's alpha is the most widely used measure of reliability [37] and is used in the present research. Cronbach's alpha $(\alpha)$ is an index used to estimate the reliability of a scale containing several items. The closer $(\alpha)$ is to 1.00 , the greater the internal consistency of the items in the instrument being assessed; $(\alpha)$ will generally increase when the correlations between the items increase. The lower acceptable limits of $(\alpha)$ are 0.50 and 0.60 , which were suggested by [38]. The complete $(\alpha)$ values for the reliability analysis are shown in Table 2 . The result shows the scale values achieved from the survey are reliable. Attributes "accessibility" and "installation sequence" showed a relatively low reliability coefficient but within acceptable range $(0.5<\alpha<0.6)$ and thus their results were included in the model.

\subsection{Constructability Factor Weight Based on Questionnaire}

Based on the 15 received responses, pair wise comparison matrixes are developed for each hierarchy level based 
Table 2. Reliability analysis.

\begin{tabular}{ccc}
\hline Main Attributes & Cronbach's $(\boldsymbol{\alpha})$ & Reliability \\
\hline Standardization & 0.949 & High \\
Economical Impact & 0.651 & High \\
Accessibility & 0.572 & Low (within acceptable range) \\
Constructability Consideration & 0.866 & High \\
Effect on Constructability & 0.624 & High \\
Installation Sequence & 0.596 & Low (within acceptable range) \\
\hline
\end{tabular}

on the AHP methodology proposed by Saaty [22]. The AHP method has been widely applied in various fields of the building industry such as facility management benchmarking [39], asset management [40], piles productivity [41], procurement selection [42], contractor selection [43], project management [44] and maintenance management [45]. The technique structures a decision problem into a hierarchy of criteria, sub-criteria and alternatives, followed by a series of pair wise comparisons among all the criteria with respect to the goal. These comparisons will derive the local priority ratios as proxy of the priority vectors for the criteria. These pair-wise comparisons are made using a nine-point scale [22]:

$1=$ Equal importance or preference.

3 = Moderate importance or preference of one over another.

$5=$ Strong or essential importance or preference.

7 = Very strong or demonstrated importance or preference.

$9=$ Extreme importance or preference.

The "priority vector" (i.e. the normalized weight) is calculated for each criterion using the geometric mean of each row in the matrix divided by the sum of the geometric means of all the criteria. According to Saaty [22], the priority vectors can be calculated by multiplying the " $\mathrm{n}$ " judgments in each row and taking the nth root, followed by normalizing the resulting numbers. This process is then repeated for the alternatives comparing them one to another to determine their relative value/importance for each criterion. The calculations are easily established in a spreadsheet, and commercial software packages, which are currently available [24]. A sample questionnaire from one response is shown in Table 3, which includes all three levels.

For example, Design Attributes (Level \#1) are of moderate/ strong importance over Construction Attributes, and are of extreme importance over Site Impacts Attributes. Standardization (Level \#2) is of equal/moderate importance over Impacts on Adjacent Structure. Material Accessibility (Level \#3) is of moderate importance over Equipment Accessibility. Then normalization is applied to get weights for each pair.

After performing all the needed matrices, the weight of each factor is calculated by multiplying its local weight by the weight of its up-level sub-factor. The weight of each factor is the average of weights of all the 15 responses and the final result is recorded in Table 4. As shown in the table, prefabrication factor has the highest value based on the fact that design attributes shows the highest ranking. The lowest ranked factor is time underground which means that it has minimum impact on constructability. These weights are essential for running the model as their respective values have a direct impact on the overall constructability score.

Consistency Ratio (CR) calculations are performed on all weights to check the internal consistency of the judgments that have been entered to the AHP matrix calculations. Saaty [22] proved that for consistent reciprocal matrix, the largest eigen value is equal to the size comparison matrix. A measure of consistency, called Consistency Index is proposed as deviation or degree of consistency using the CR formula. In the present paper, all (CR) calculations were found to be within acceptable limits $(<0.1)$ for all the 16 factors from the 15 responses, and thus the factors' weights were then incorporated in the proposed model. The process can be referred to [41].

\subsection{BIM and 4D Model Development}

Based on the definition of BIM, data used for executing the construction drawings are linked to their respective design components. The following points show how building elements' specifications are used and modified as to provide constructability input for the assessment model. 
Table 3. Sample questionnaire for pair wise comparison.

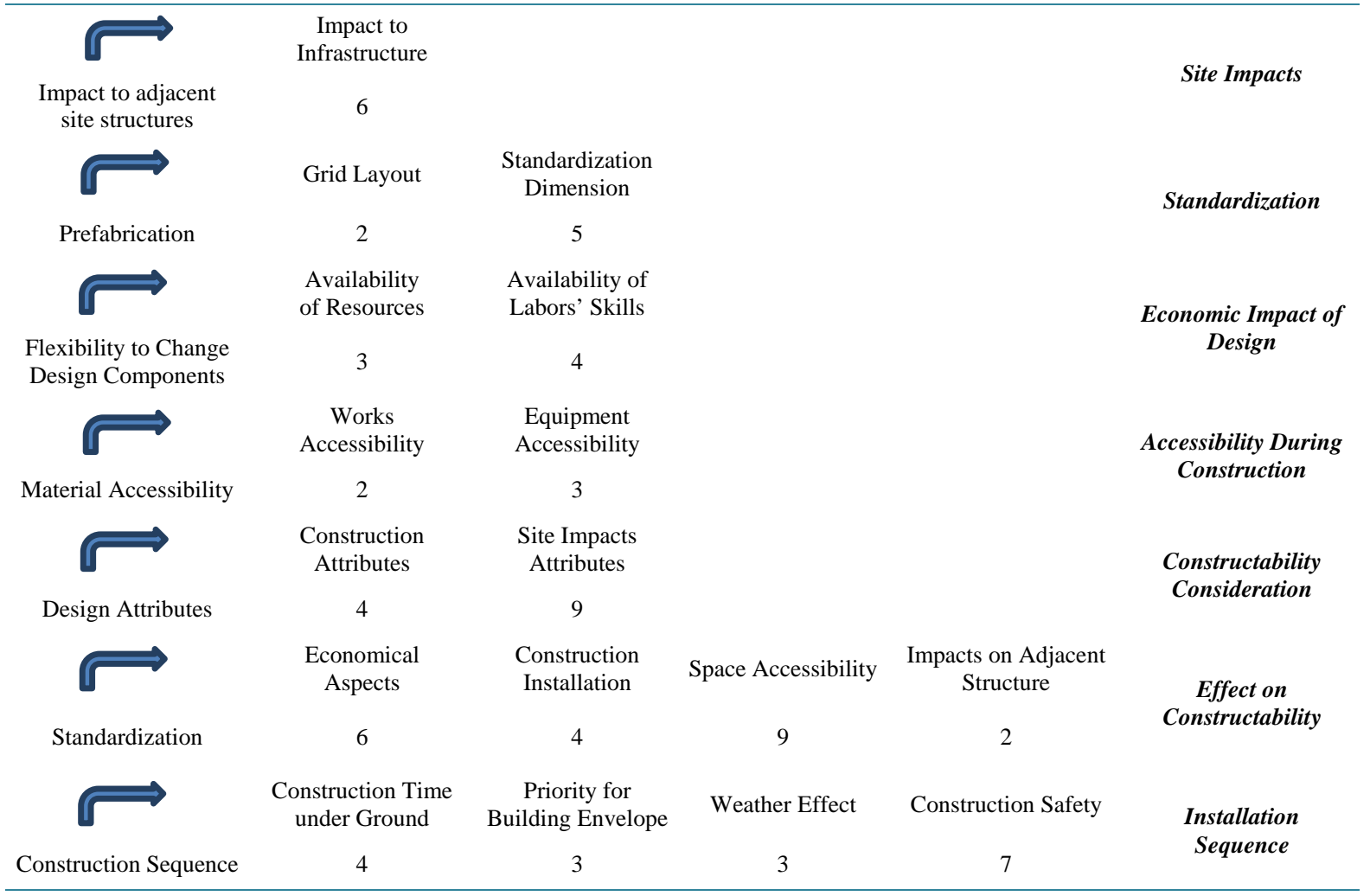

Table 4. Constructability factor weight.

\begin{tabular}{|c|c|c|c|c|c|c|}
\hline Level \#1 & Weight & Level \#2 & Weight & Level \#3 & Weight & $\frac{\text { Decomposed }}{\underline{\text { Weight }}}$ \\
\hline \multirow{6}{*}{ Design Attributes } & \multirow{6}{*}{0.667} & \multirow{3}{*}{ Standardization } & \multirow{3}{*}{0.788} & Prefabrication & 0.575 & 0.302 \\
\hline & & & & Grid Layout & 0.282 & 0.148 \\
\hline & & & & Standard Dimensions & 0.143 & 0.075 \\
\hline & & \multirow{3}{*}{ Economical Impact } & \multirow{3}{*}{0.212} & Components' Flexibility & 0.611 & 0.086 \\
\hline & & & & Resources’ Availability & 0.173 & 0.025 \\
\hline & & & & Labour's Skills & 0.216 & 0.031 \\
\hline \multirow{8}{*}{$\begin{array}{l}\text { Construction } \\
\text { Attributes }\end{array}$} & \multirow{8}{*}{0.181} & \multirow{5}{*}{ Installation } & \multirow{5}{*}{0.514} & Construction Sequence & 0.514 & 0.048 \\
\hline & & & & Time under Ground & 0.087 & 0.008 \\
\hline & & & & Building Envelope & 0.123 & 0.011 \\
\hline & & & & Weather Effect & 0.151 & 0.014 \\
\hline & & & & Safety & 0.126 & 0.012 \\
\hline & & \multirow{3}{*}{ Accessibility } & \multirow{3}{*}{0.486} & Material Access & 0.606 & 0.053 \\
\hline & & & & Personnel Access & 0.214 & 0.019 \\
\hline & & & & Equipment Access & 0.180 & 0.016 \\
\hline \multirow{2}{*}{ Site Impacts } & \multirow{2}{*}{0.152} & \multirow{2}{*}{ Adjacent Structures } & \multirow{2}{*}{1.000} & To Adjacent Foundation & 0.720 & 0.110 \\
\hline & & & & To Infrastructure & 0.280 & 0.043 \\
\hline
\end{tabular}


Design attributes: Figure 3(a) shows a typical exterior wall with a stone exterior finish. The window associated in this wall is an ellipse shaped one with a fixed glass panel. Assuming that the elliptic window installation needs a specialized skilled labor, stone material is unavailable, equipments to fix the window are unavailable and the wall component is fabricated on-site, Figure 3(b) shows how these design and construction information is transformed to constructability input in the BIM model.

- Component's Flexibility: Flexibility rationales identified in previous subsection are interpreted in Figure 4. The dotted arrows shows that the designated internal walls have a potential for change concerning position, where the arrows with the cross sign found besides the external walls show that there is no potential for change. The arrows with question marks on the walls dividing the 2 apartments show that a decision must be made concerning the effect of changing the position of this internal partition on the two nearby spaces. Concerning building materials, each building component can be studied alone to figure out whether there is a potential for material change or not. The sink component in the kitchen can be revolved around its center and thus its position flexibility can be highly achieved. All of these analyses are made by the design team on the BIM model concerning a particular given design and then transferred to constructability input values. Input values can be made for each component alone or per family. For example, all internal partition walls with width $=125 \mathrm{~mm}$ and a fire rated protection $=2 \mathrm{H}$ can be considered as a single family and have the same constructability input concerning flexibility. Figure 5 shows how flexibility attributes' values are recorded in BIM model. To improve flexibility of designs, designers have to check their building components against flexibility rationale criteria and record the findings in the modified BIM property panel for each design element.

- Automatic constructability rules: BIM parametric features are very helpful in identifying and modifying constructability aspects in a design. Parametric relationship between design components means that they have a logical interconnection between them. This aspect is considered one of the most important features of a BIM model. In other words, if the user changes a particular building component, any linked component to it will be updated automatically, thus preventing rework, reducing modification time and increasing accuracy of the design. Figure 6 shows a space annotation "Lounge Room" as a part of different spaces included in a

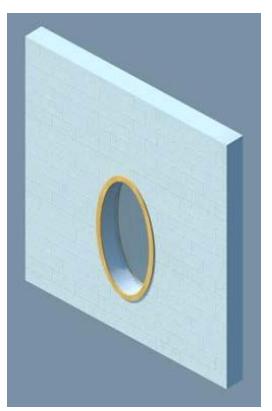

(a)

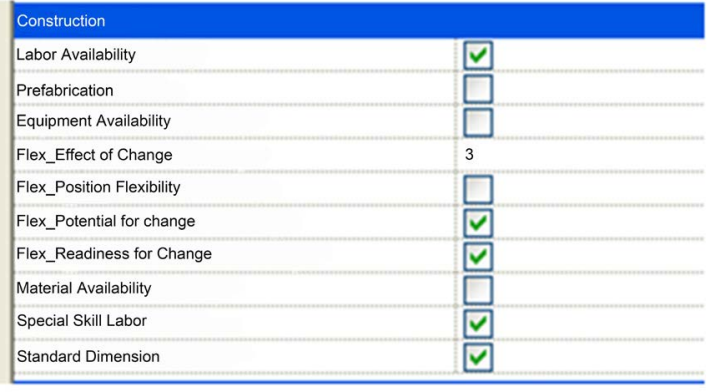

(b)

Figure 3. Constructability input for wall example.

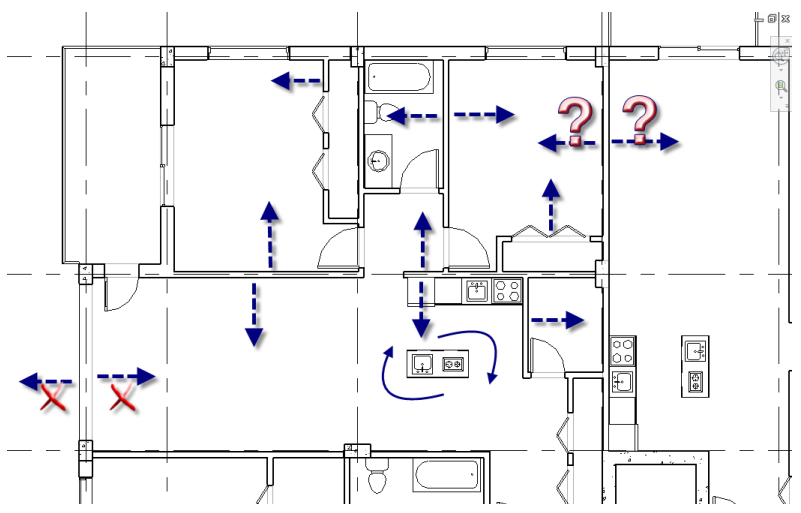

Figure 4. Flexibility analysis for a typical apartment design. 
building. Design specification, rules and regulations or any other needed construction data are linked to this particular space and used for the constructability analysis. For example, details like finishing material, ceiling height, construction equipment involved, utilities, etc., are used in identifying the space characteristics. Constructability input is added to this space and used as a basic rule for the project; thus all spaces with the same name and function have the same constructability input. The benefit is that a single data modification for a specific defined space will be automatically applied to all spaces that have the same specification. The same concept is applied to all kind of spaces: toilets, kitchens, corridors, emergency exists, etc. In Figure 6, all of the construction data of the design components incorporated in Lounge Room are saved in the BIM model using the characteristics of "family" and "type". Any data entry to the defined space "Lounge Room" will be applied automatically to all building components associated in this space.

- Working space allocation: Working spaces like storage areas or fabrication area can be identified in the design phase and linked to their associated design components. Figure 7 shows a typical fabricated space area associated with its designated building element, e.g., a wall. When the user modifies the location of the wall, working space areas are automatically moved together since working space areas are linked parametrically to their associated components.

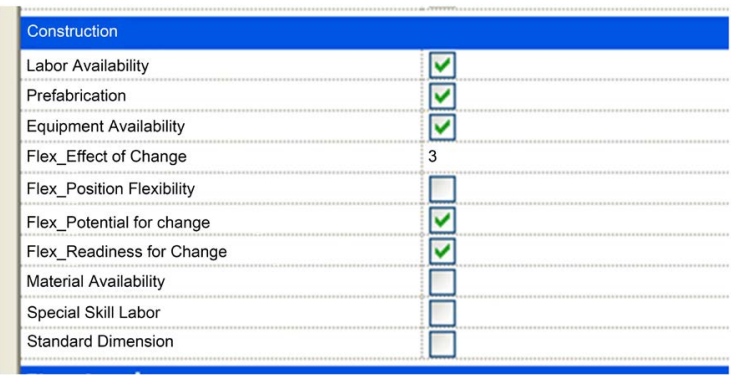

Figure 5. Flexibility attribute values recorded in BIM model.

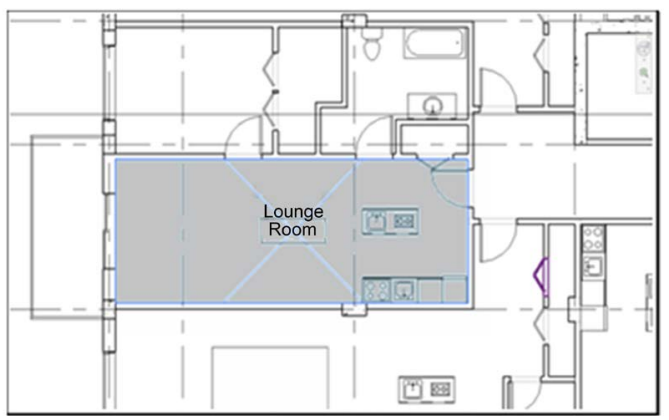

Figure 6. Analyzing constructability aspect using bim parametric features.

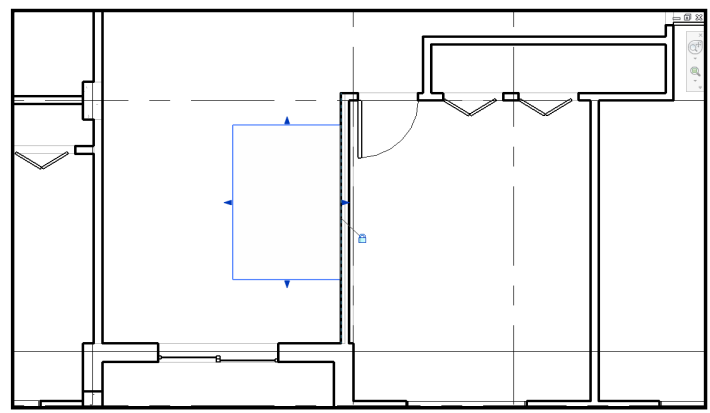

(a)

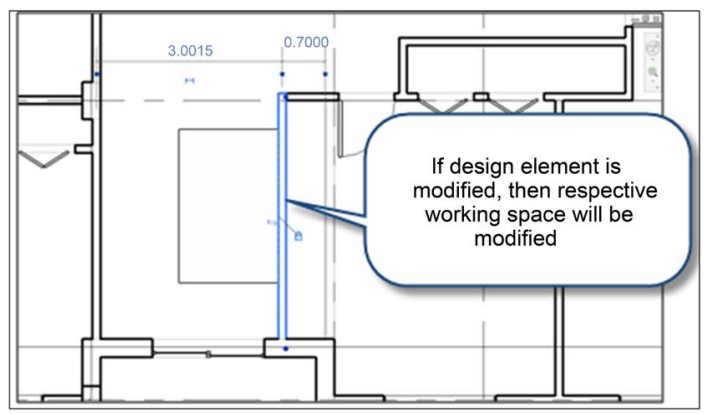

(b)

Figure 7. Working space linked to building elements. (a) Working space associated to a wall; (b) Working space modified automatically. 
As explained in previous subsection, a 4D model is used to test the effect of time on any given 3D model so that factors like resources accessibility and construction sequence or building envelope can be analyzed. Time schedule is developed based on the plan for executing the project. The more details the schedule has, the better the output gained from the 4D model. Each scheduled activity is linked to its corresponding building component. Since the whole constructability assessment is done during early phases of the project, it is not necessary that the schedule is in its final form. In the present research, NavisWorks $@$ is used for developing the 4D simulation. The simulation is in the form of a video where the user can see the sequence of construction in an animated form. Snap-shots from the model can also be used for detailed analysis. The visualization output of the 4D model can be adjusted as to meet the specific requirements of the constructability test proposed by the design team. For example, if activities underground are considered a single phase and needs to have a separate constructability feedback, the 4D model can be adjusted to only simulate the underground activities.

BIM models save each design component's information with a unique component ID, so that no conflicts occur when dealing with data exchange. Based on this ID uniqueness feature, all components' characteristics can be exported from the BIM model and imported to the data model. Microsoft Access@ is used to develop the data model which will be needed for both the assessment model and the user-friendly tool. After importing all the building data to the Access $\odot$ based model, each constructability factor will have a "one to many" relationship with all BIM components that are associated with this particular factor. Thus, when it comes to the assessment of a certain constructability factor, only the needed information will be presented for that factor and not the entire output of the BIM model. In addition to the unique ID that each design component has, BIM components also have 2 important characteristics: family and type. Family represents the main description of components like wall, door, window, etc... while type represents a specific kind of family component like: internal wall 1 hour fire rated or wooden door single flush panel. The developed data model used these 2 aspects of BIM components to categorize the whole design components.

After developing the BIM and the 4D model, all the output are exported to a single data model in the form of general constructability output. In the data model, which is generated using Access $\subseteq$, the general data is categorized and distributed based on the proposed criteria rationale for each factor and as per the data model development process. Using Access $\subseteq$ application, constructability information is analyzed using one of the two techniques: Quarry and Checklist. Quarries are based on simple mathematical calculations (sum, average) and are used to simplify the generated quantities from the BIM model. The output of these queries is used to evaluate constructability attributes based on the project rating criteria that are proposed in the present paper. Checklist is another method to analyze the output data and $t$ it contains attributes related to only 4 constructability factors. This method is proposed because the rationale behind these factors is based on specific identified points. By identifying the number of checked or unchecked attributes found in the lists the analysis of the corresponding factor is possible. Thus, by evaluating the results of either the quarries or the checklists, the user can rate the impact of the constructability factor on design using the rating scale and criteria provided for the studied factor.

The last step in this process is to transform the ratings into utility values using the unified SMART rating scale and weights shown in Table 4. As shown in Figure 8, Constructability index reflects the impact value of a particular factor on the overall constructability score and is calculated using a generic equation: $\mathrm{C}_{\text {index }}=\mathrm{W} \times \mathrm{U}$. The total constructability score $\mathrm{Ct}$ is calculated by summing up all the 16 individual $\mathrm{C}_{\mathrm{i}}$. More details can be found in Hijazi [11].

\section{Case Study}

The proposed methodology is applied to a construction project located in Montreal (Carterville), Canada. Revit $\subseteq$ is used to generate the BIM model, while NavisWorks $\odot$ is used to simulate the schedule in the 4D model. Only architectural aspects were considered in this case study for simplicity reasons. The BIM model was developed based on completed plans and available construction data (material, partition specification, dimensions, etc...). All unavailable data needed to generate the BIM model were assumed. The Revit $\subseteq$ software used contains the modified shared parameters that are explained in previous subsection. Since all design components have parametric relationship with each other, sections, elevations and other details were generated automatically as shown in Figure 9.

Figure 10 shows the prefabrication assessment interface. The model showed that $49.72 \%$ of the whole building components are prefabricated components. General constructability rules states that the more the prefabri- 

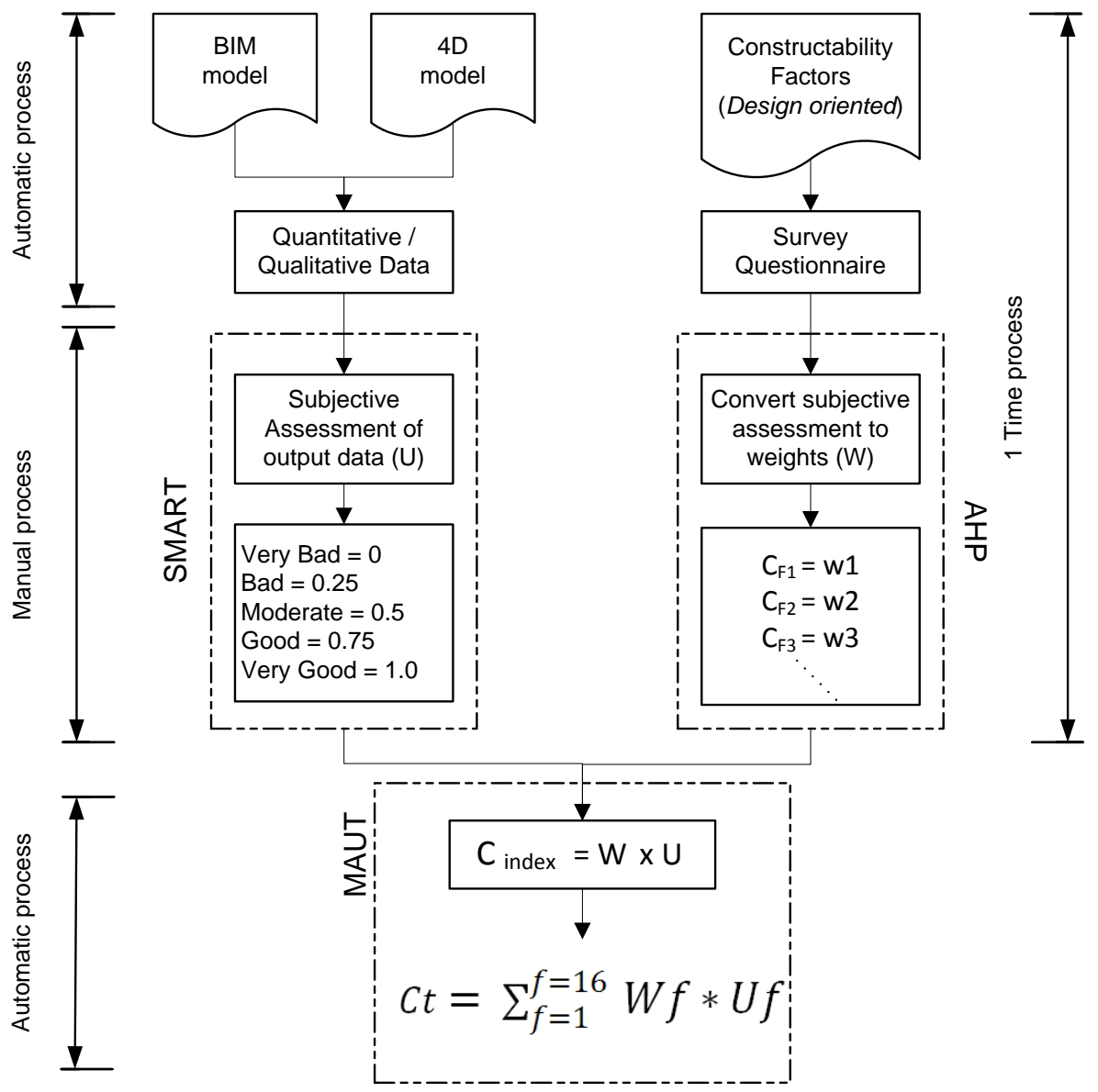

Figure 8. Integration of AHP and SMART in the model.

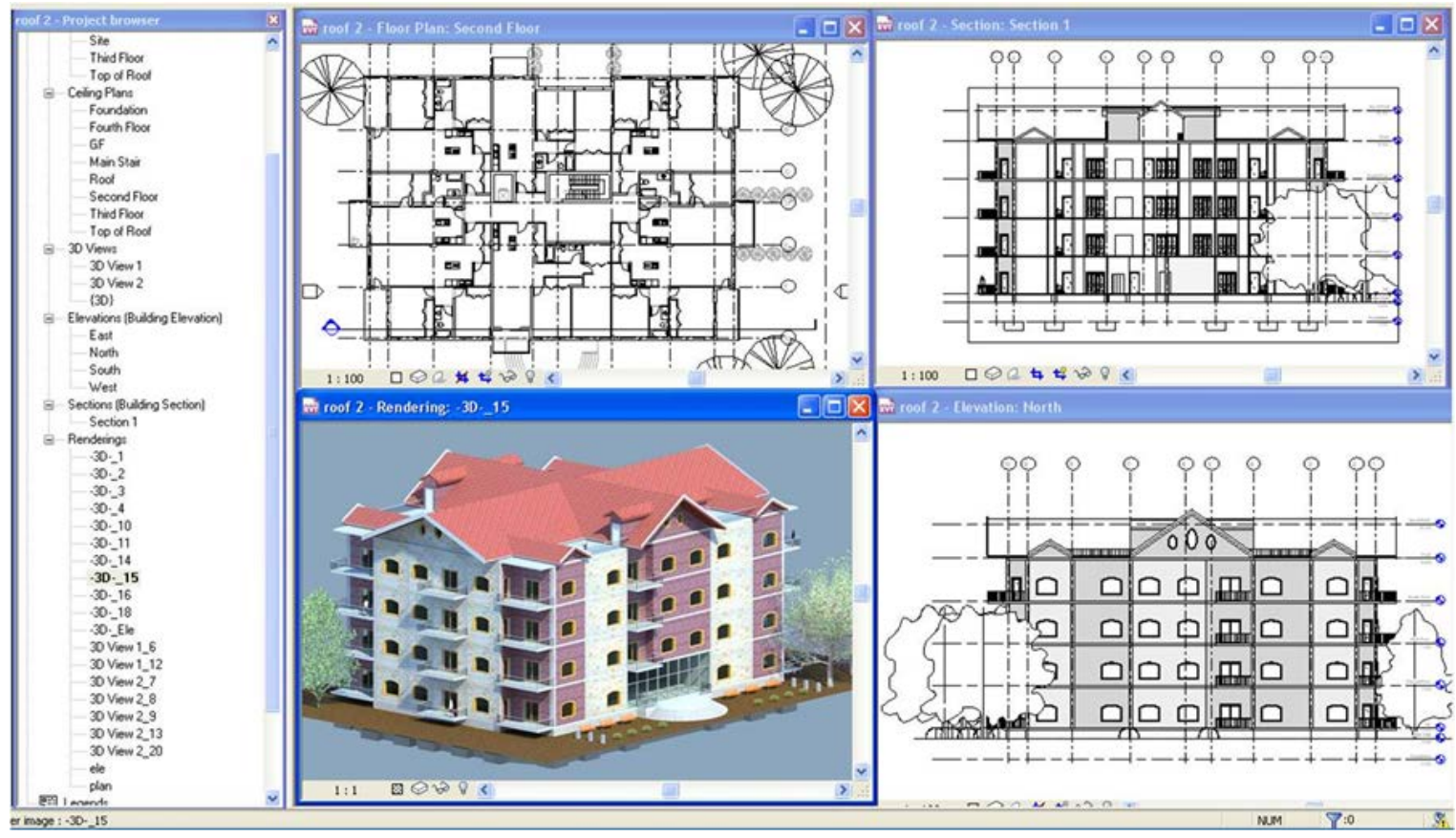

Figure 9. Sections and elevations. 
C. Zhang et al.

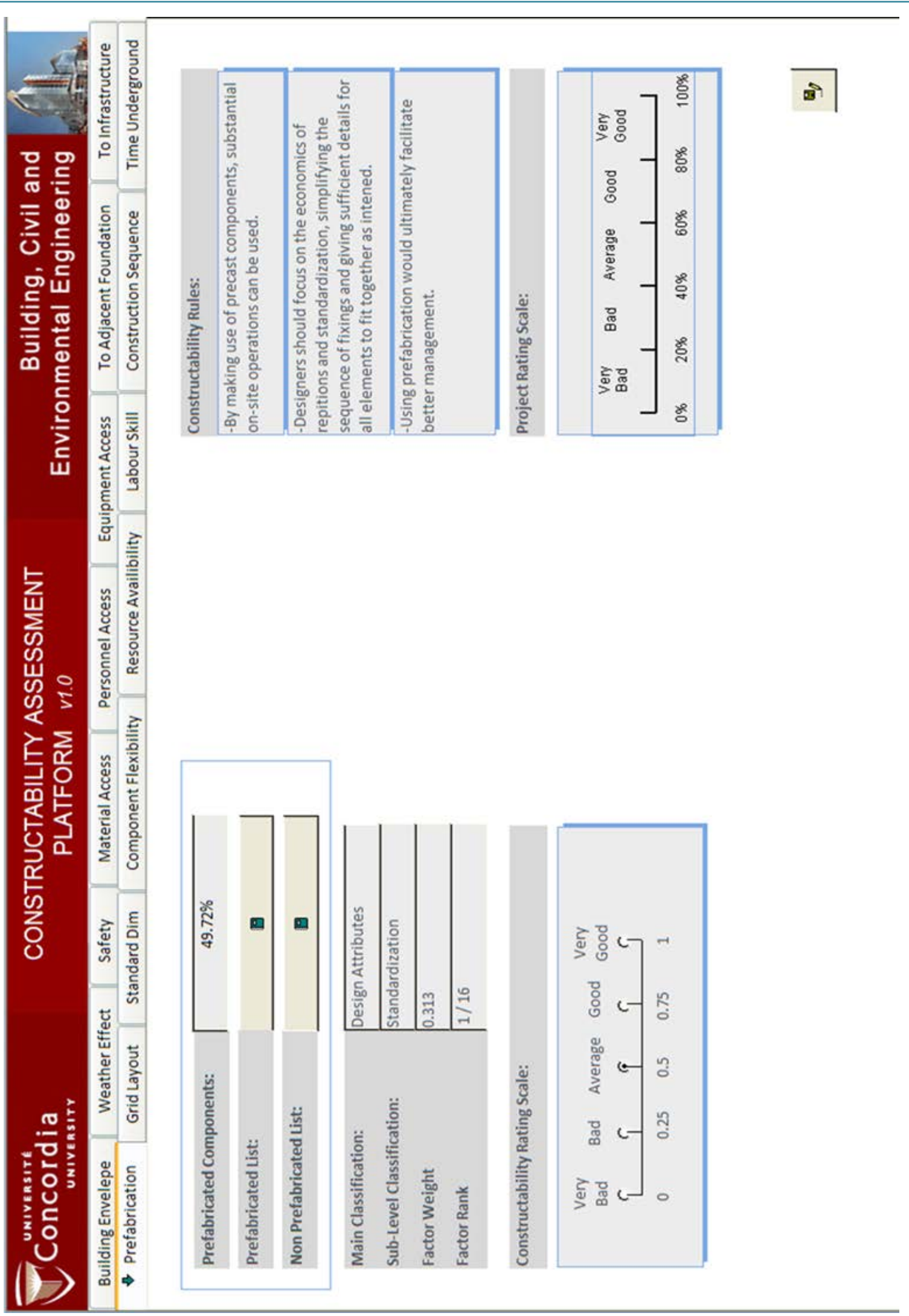

Figure 10. Constructability assessment for prefabrication factor. 
cated components are, the more the positive impact on constructability is. Based on the project rating scale for this factor, $49.72 \%$ falls in the average criteria. The average criteria as per the constructability rating scale is equivalent to a utility value of $U=0.5$. The weight of this factor $\mathrm{W}=0.313$, thus the Constructability index $\mathrm{C}_{\mathrm{i}}=$ $0.5 \times 0.313=0.157$. The weight calculated in the assessment model is given as 0.157 .Detailed report for prefabricated and non-prefabricated components are generated and used to identify what elements can be modified as to improve the prefabricated components' percentage and thus improving constructability. The same process is applied for all the other factors.

The factor Components' Flexibility was also studied. The BIM model identified $76.89 \%$ as a flexibility ratio of the design. Three reports were provided for this factor so identify which components had low, medium or high negative impact on the design in case a change in the components' specification is required. The weather effect factor was studied using the 4D model. Sixty-seven days during the construction project period were assumed to be extremely bad weather days where a high probability of interruption or delay can affect exterior works activities. The 4D model showed that there are exterior work activities in 26 days out of the 67 days which gives a ratio of $38.8 \%$. This ratio falls in the good rating criteria and gives a utility value of 0.75 . The safety factor was assessed using the constructability checklist. Based on the output of the two models, 7 out of 9 identified safety issues were checked which gives a ratio of $77 \%$ and thus the safety rating was concluded to be good. The personnel access factor was assessed in the same manner. The analysis of 4 construction phases identified the need for 14 different space allocations. The visual simulation of the 4D model showed a conflict in 6 spaces only which gives a ratio of $42.8 \%$ and thus the rating of this factor is average.

These assessments were done for the first proposed design alternative and the constructability score showed an overall score of 0.740 out of 1 which is evaluated as good based on the scale provided with the report. This scale uses the same ratings as the SMART scale. The interpretation of the final score is based on the constructability requirements proposed for this design and thus this design rated good. Improving constructability of design can be done by studying the indexes achieved from the $1^{\text {st }}$ assessment. Figure 11 shows how each factor contributed to the overall calculated score. These calculations are based on the ratio of each index to the score. For example: $C_{i}$ prefabrication $=0.1510$, and the overall score $=0.7460$, thus the percentage of contribution $=$ $20.24 \%$. This generated graph helps in identifying which factors and components have to be modified in order to improve the result.

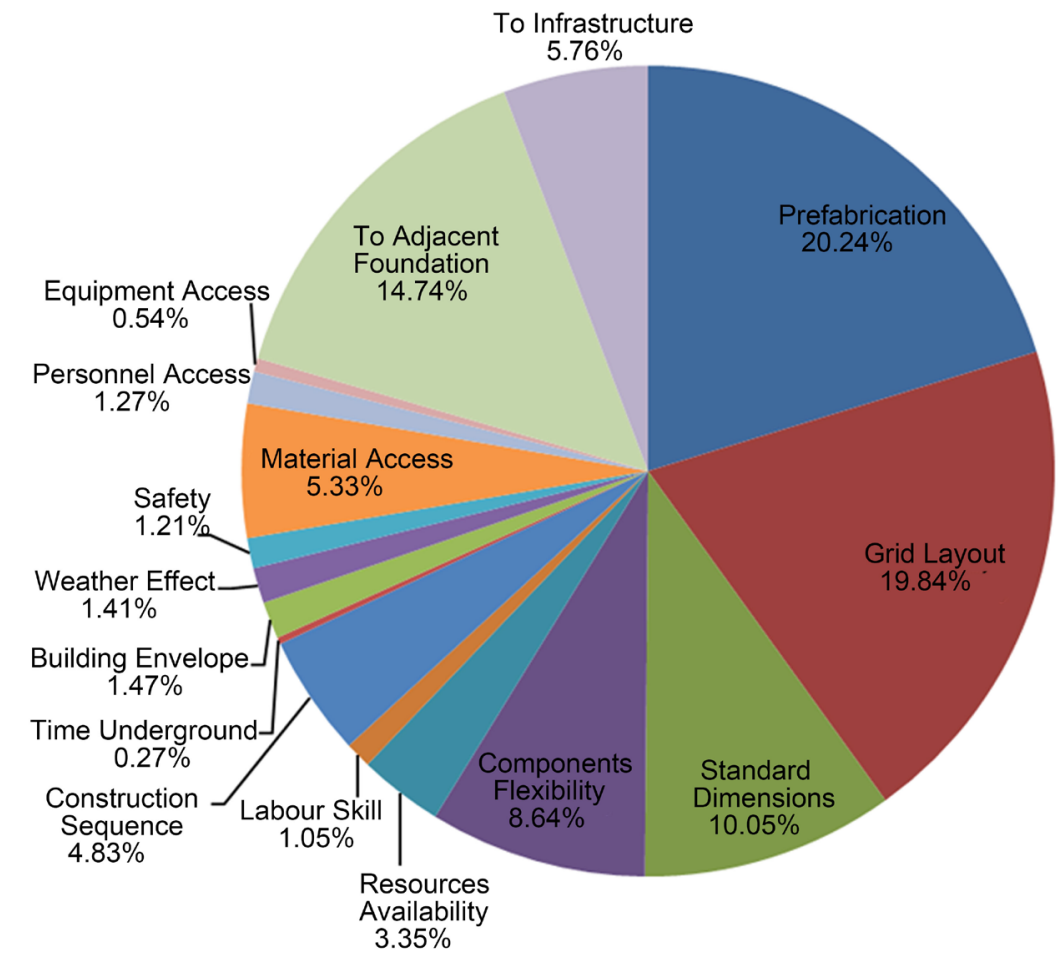

Figure 11. Percentage of each factor's contribution to overall score. 


\section{Conclusion}

This work proposes a methodology that addresses the challenge faced by construction stakeholders concerning constructability improvement of projects. It offers a platform to assess constructability of building designs. The assessment model considers many design relevant factors, which can be divided broadly into 3 main categories: design, construction and impact on site attributes. Based on 8 constructability principles, 16 design factors are incorporated in the model (qualitative and quantitative factors). In addition to the assessment model, a platform to improve constructability of design is proposed. This method relies on the use of advanced technology tools used in the construction field, which are BIM and 4D models. AHP is used to relatively weight the factors incorporated in the model based on a survey questionnaire done throughout different Canadian provinces. Based on the developed assessment model and the proposed implementation method, an Access@-based tool is developed to assess and evaluate constructability of designs. Owners, designers and contractors can use the developed application to improve the constructability of proposed building designs and thus reduce overall time and cost consumption during construction phases. The developed platform addresses the problem of assessing the abstract nature of constructability principles in any given object oriented BIM. It contributes to the field of construction management by achieving the following: (1) A new assessment model to quantitatively evaluate constructability of designs; (2) A new technique to check for constructability implementation in designs that helps owners, designers and contractors integrate their ideas based on state of the art advancement in the construction industry; (3) An automated tool that helps project stakeholders evaluate many design alternatives to achieve maximum possible constructible projects in a quantified manner; and (4) Broadens the usage of objected oriented models as to follow up with the state of the art of BIM evolution in the construction industry and promotes the integration between BIM and 4D models tools for the purpose of constructability analysis.

\section{References}

[1] Business Roundtable (1982) Integrating Construction Resources and Technology into Engineering. Report No. B-1A, Construction Industry Cost Effectiveness Project Report, New York.

[2] Gallaher, M. (2004) Cost Analysis of Inadequate Interoperability in the US Capital Facilities Industry. Report No. NIST GCR 04-867, NIST. http://dx.doi.org/10.6028/NIST.GCR.04-867

[3] CIRIA: Construction Industry Research and Information Association (1983) Buildability: An Assessment. CIRIA, London.

[4] Lam, P.T.I., Chan, A.P.C., Wong, F.K.W. and Wong, F.W.H. (2007) Constructability Rankings of Construction Systems Based on the Analytical Hierarchy Process. Journal of Architectural Engineering, 13, 36-43. http://dx.doi.org/10.1061/(ASCE)1076-0431(2007)13:1(36)

[5] Wong, F.W.H., Lam, P.T.I., Chan, E.H.W. and Shen, L.Y. (2007) A Study of Measures to Improve Constructability. International Journal of Quality \& Reliability Management, 24, 586-601. http://dx.doi.org/10.1108/02656710710757781

[6] Eastman, C., Teicholz, P., Sacks, R. and Liston, K. (2008) BIM Handbook: A Guide to Building Information Modeling for Owners, Managers, Designers, Engineers and Contractors. John Wiley \& Sons, Inc., Hoboken. http://dx.doi.org/10.1002/9780470261309

[7] Gambatese, J., Dunston, P.S. and James, B.P. (2007) The Way Forward: Recommendation for Future Constructability Research and Practice. In: Gambatese, J., Pocock, J. and Dunston, P., Eds., Constructability Concepts and Practices, American Society of Civil Engineers, Reston, 142-145. http://dx.doi.org/10.1061/9780784408957.ch09

[8] Zin, R.M., Nesan, L.J. and Mohammed, A.H. (2004) Constructability Assessment Framework. Journal of Building and Construction Management, 9, 44-58.

[9] Ugwu, O.O., Anumba, C.J. and Thorpe, A. (2004) The Development of Cognitive Models for Constructability Assessment in Steel Frame Structures. Advances in Engineering Software, 35, 191-203. http://dx.doi.org/10.1016/j.advengsoft.2004.02.001

[10] Yang, Y.Q., Wang, S.Q., Dulaimi, M. and Low, S.P. (2003) A Fuzzy Quality Function Deployment System for Buildable Design Decision-Makings. Automation in Construction, 12, 381-393. http://dx.doi.org/10.1016/S0926-5805(03)00002-5

[11] Hijazi, W.M. (2009) Constructability Assessment Platform Using Customized BIM and 4D Models. MSc Thesis, Department of Building, Civil, and Environmental Engineering, Concordia University, Montreal.

[12] Hartmann, T. and Fischer, M. (2007) Supporting the Constructability Review with 3D/4D Models. Building Research 
and Information, 35, 70-80. http://dx.doi.org/10.1080/09613210600942218

[13] Krygiel, E., Nies, N. and McDowell, S. (2008) Green BIM: Successful Sustainable Design with Building Information Modeling. Wiley Publishing, Indianapolis.

[14] Khemlani, L. (2004) The IFC Building Model: A Look under the Hood. http://home.fa.utl.pt/ franc/2007/mapoio/projdig/Ifcmodel.pdf

[15] Koo, B., Fischer, M. and Kunz, J. (2007) Formalization of Construction Sequencing Rationale and Classification Mechanism to Support Rapid Generation of Sequencing Alternatives. Journal of Computing in Civil Engineering, 21, 423433. http://dx.doi.org/10.1061/(ASCE)0887-3801(2007)21:6(423)

[16] Echeverry, D., Ibbs, C.W. and Kim, S. (1991) Sequencing Knowledge for Construction Scheduling. Journal of Construction Engineering and Management, 117, 118-130. http://dx.doi.org/10.1061/(ASCE)0733-9364(1991)117:1(118)

[17] Staub, S. and Fischer, M. (1998) Constructability Reasoning Based on a 4D Facility Model. Proceedings of Structural Engineering World Congress, San Francisco, 1998.

[18] Lee, A., Wu, S., Marshall, A., Aouad, G., Tah, J., Cooper, R. and Fu, C. (2005) ND Modelling-A Driver or Enabler for Construction Improvement? RICS Research Paper Series, 5, 1-16.

[19] Hijazi, W.M., Alkass, S. and Zayed, T. (2009) Constructability Assessment Using BIM/4D CAD Simulation Model. Proceedings of the AACE's 2009 Annual Meeting, Seattle, 28 June-1 July 2009.

[20] Hijazi, W.M., Alkass, S. and Zayed, T. (2009) Constructability Assessment Framework Using BIM Technology. Proceedings of the 8th Construction Specialty Conference, St. John's, Newfoundland and Labrador, 27-30 May 2009.

[21] CII Construction Industry Institute (1986) Constructability: A Primer. Construction Industry Institute, University of Texas, Austin.

[22] Saaty, T.L. (1994) How to Make a Decision-The Analytic Hierarchy Process. Interfaces, 24, 19-43. http://dx.doi.org/10.1287/inte.24.6.19

[23] Edwards, W. (1977) How to Use Multiattribute Utility Measurement for Social Decisionmaking. IEEE Transactions on Systems, Man, and Cybernetics, 7, 326-340. http://dx.doi.org/10.1109/TSMC.1977.4309720

[24] Edwards, W. and Barron, F.H. (1994) SMARTs and SMARTER; Improved Simple Methods for Multiattribute Utility Measurement. Organizational Behavior and Human Decision Processes, 60, 306-325. http://dx.doi.org/10.1006/obhd.1994.1087

[25] Ferguson, I. (1989) Buildability in Practice. Mitchell, London.

[26] Building and Construction Authority (BCA) (2013) Code of Practice on Buildaility. Building and Construction Authority, Singapore.

[27] Griffith, A. and Sidwell, A.C. (1997) Development of Constructability Concepts, Principles and Practices. Engineering, Construction \& Architectural Management, 4, 295-310. http://dx.doi.org/10.1108/eb021054

[28] Nima, M.A., Abdul-Kadir, M.R. and Jaafar, M.S. (1999) Evaluation of the Engineer's Personnel's Role in Enhancing the Project Constructability. Facilities, 17, 423-430. http://dx.doi.org/10.1108/02632779910291895

[29] Adams, S. (1989) Practical Buildability. Butterworths/CIRIA, Sevenoaks.

[30] Tatum, C.B. (1988) Classification System for Construction Technology. Journal of Construction Engineering and Management, 114, 344-363. http://dx.doi.org/10.1061/(ASCE)0733-9364(1988)114:3(344)

[31] Hass, C., O’Connor, J.T., Tucker, R.L., Eickmann, J. and Fagerlund, W. (2000) Prefabrication and Preassembly Trends and Effects on the Construction Workforce. Report No. 10, Center for Construction Industry Studies, University of Texas at Austin, Austin.

[32] Song, J., Fagerlund, W.R., Haas, C.T., Tatum, C.B. and Vanegas, J.A. (2005) Considering Prework on Industrial Projects. Journal of Construction Engineering and Management, 131, 723-733. http://dx.doi.org/10.1061/(ASCE)0733-9364(2005)131:6(723)

[33] Schneeweiss, C. and Schneider, H. (1999) Measuring and Designing Flexibility as a Generalized Service Degree. European Journal of Operation Research, 112, 98-106. http://dx.doi.org/10.1016/S0377-2217(97)00380-9

[34] Rajan, P.K., Van, M., Matthew, C.I., Kristin, W.L. and Kevin, O.N. (2005) An Empirical Foundation for Product Flexibility. Design Studies, 26, 405-438. http://dx.doi.org/10.1016/j.destud.2004.09.007

[35] Hinze, J. and Wiegand, F. (1992) Role of Designers in Construction Worker Safety. Journal of Construction Engineering and Management, 118, 677-684. http://dx.doi.org/10.1061/(ASCE)0733-9364(1992)118:4(677)

[36] Riley, D.R. and Sanvido, V.E. (1995) Patterns of Construction-Space Use in Multistory Buildings. Journal of Construction Engineering and Management, 121, 464-473. http://dx.doi.org/10.1061/(ASCE)0733-9364(1995)121:4(464) 
[37] Wei, M., Russell, D.W., Mallinckrodt, B. and Vogel, D.L. (2007) The Experiences in Close Relationship Scale (ECR)Short Form: Reliability, Validity, and Factor Structure. Journal of Personality Assessment, 88, 187-204. http://dx.doi.org/10.1080/00223890701268041

[38] Kaplan, R.M. and Saccuzzo, D.P. (1993) Psychological Testing. 3rd Edition, Brooks/Cole Publishing Company, Pacific Grove.

[39] Gilleard, J.D. and Wong, Y.P. (2004) Benchmarking Facility Management: Applying Analytic Hierarchy Process. Facilities, 22, 19-25. http://dx.doi.org/10.1108/02632770410517915

[40] Tran, T.M., Malano, H.M. and Thompson, R.G. (2003) Application of the Analytic Hierarchy Process to Prioritise Irrigation Asset Renewals: The Case of the La Khe Irrigation Scheme, Vietnam. Engineering, Construction and Architectural Management, 10, 382-390. http://dx.doi.org/10.1108/09699980310509354

[41] Zayed, T. and Halpin, D. (2004) Quantitative Assessment for Piles Productivity Factors. Journal of Construction Engineering and Management, 130, 405-414. http://dx.doi.org/10.1061/(ASCE)0733-9364(2004)130:3(405)

[42] Al-Khalil, M.I. (2002) Selecting the Appropriate Project Delivery Method Using AHP. International Journal of Project Management, 20, 464-469. http://dx.doi.org/10.1016/S0263-7863(01)00032-1

[43] Fong, P.S. and Choi, S.K. (2000) Final Contractor Selection Using the Analytical Hierarchy Process. Construction Management and Economics, 18, 547-557. http://dx.doi.org/10.1080/014461900407356

[44] Al-Harbi, K. (2001) Application of the AHP in Project Management. International Journal of Project Management, 19, 19-27. http://dx.doi.org/10.1016/S0263-7863(99)00038-1

[45] Shen, Q., Lo, K. and Wang, Q. (1998) Priority Setting in Maintenance Management: A Modified Multi-Attribute Approach Using Analytic Hierarchy Process. Construction Management and Economics, 16, 693-702. http://dx.doi.org/10.1080/014461998371980 